\title{
Late recurrence of a giant left ventricular pseudoaneurysm: the importance of multimodality imaging approach
}

\author{
Antonio Landi ${ }^{1}$, Anto Luigi Andres ${ }^{2}$, Massimo Napodano ${ }^{3}$ \\ ${ }^{1}$ Cardiovascular Department, IRCCS Multimedica, Milan; ${ }^{2}$ Radiology Unit, Padua Hospital, Padua; ${ }^{3}$ Department of \\ Cardiac, Thoracic and Vascular Science, University of Padua Medical School, Padua, Italy
}

\begin{abstract}
Left ventricular pseudoaneurysms (LVP) are rare but may arise after myocardial infarction, trauma or cardiac surgery, tending to expand and rupture over the time. We show the case of a 75year-old patient with a recurrent giant ventricular pseudoaneurysm, who presented to the emergency department with sustained ventricular tachycardia. Pseudoaneurysmatic lesion was investigated through echocardiography, angiography and Cardiac Computed Tomography, in order to evaluate the size and spatial orientation of the pseudoaneurysm and to set a tailored treatment. At emergency department, sustained ventricular tachycardia may be the first and unique clinical presentation of ventricular pseudoaneurysm late recurrence, whose management requires a multimodality imaging approach to guide surgical correction.
\end{abstract}

Correspondence: Antonio Landi, Cardiology Unit, Cardiovascular Department, IRCCS Multimedica, via Milanese 300, 20099, Milan, Italy. Tel. +39.3297.038714.

E-mail: antonio.landi89@gmail.com

Contributions: AL, conceptualization, writing - original draft preparation; ALA, visualization; $\mathrm{MN}$, validation, writing - reviewing and editing. All the authors made a substantive intellectual contribution, have read and approved the final version of the manuscript and agreed to be accountable for all aspects of the work.

Conflict of interests: The Authors declare no conflict of interest.

Funding: The study was not supported by any specific funding.

Key words: Ventricular pseudoaneurysm; ventricular tachycardia; myocardial infarction; Cardiac Computed Tomography.

Received for publication: 18 January 2020.

Accepted for publication: 25 February 2020.

${ }^{\text {CC}}$ Copyright: the Author(s), 2020

Licensee PAGEPress, Italy

Monaldi Archives for Chest Disease 2020; 90:1232

doi: 10.4081/monaldi.2020.1232

This article is distributed under the terms of the Creative Commons Attribution Noncommercial License (by-nc 4.0) which permits any noncommercial use, distribution, and reproduction in any medium, provided the original author(s) and source are credited.

\section{Introduction}

Left ventricular pseudoaneurysms (LVP) are rare but may arise after myocardial infarction, trauma or cardiac surgery, leading to thromboembolism, ventricular arrhythmias, cardiac tamponade, cardiogenic shock and sudden death. We present the case of a 75year-old patient with recurrent giant ventricular pseudoaneurysm, presenting with sustained ventricular tachycardia. Then, we will discuss the crucial role of early diagnosis through multimodal imaging techniques in current management at emergency department.

\section{Case Report}

A 75-year-old man presented to our emergency department (ED) with sustained ventricular tachycardia, in absence of signs of hemodynamic instability. Ten years before, he had an inferior myocardial infarction due to complete occlusion of right coronary artery (RCA), with subsequent development of inferior LVP. He underwent surgical ventricular repair and cardioverter-defibrillator implantation for primary prevention one year later. In the following years, the patient made an uneventful recovery.

In the ED, intravenous amiodarone bolus was effective in restoring sinus rhythm. However, echocardiography revealed a giant LVP of inferolateral wall (Figure 1 A,B), close to the previous pericardial patch. Urgent left heart catheterization showed nearocclusive lesion of distal RCA and a giant pseudoaneurysm of inferior wall (red borders) with a thrombotic layer (Figure 1C, asterisks; supplementary material Video S1). Cardiac Computed Tomography (CT) confirmed that pseudoaneurysmatic lesion (maximum diameters $12 \times 5.5 \times 9.5 \mathrm{~cm}$ ) was close to the mitral valve annulus, in absence of a narrow neck (Figure 2. A,B). 3D CT reconstruction added information on the size and spatial orientation of the pseudoaneurysm, which was larger than LV chamber (Figure 2C). Taking into account the surgical risk, the patient underwent re-surgical ventricular restoration with an endoventricular bovine pericardial patch (Dor procedure). The patient made an eventful recovery and was discharged ten days after the surgical intervention. At 2-year followup, the patient is alive (New York Heart Association class II) and no further sustained ventricular arrhythmias were detected.

\section{Discussion}

Left ventricular pseudoaneurysm is a rare life-threatening complication following myocardial infarction $(42-100 \%$ of cases 

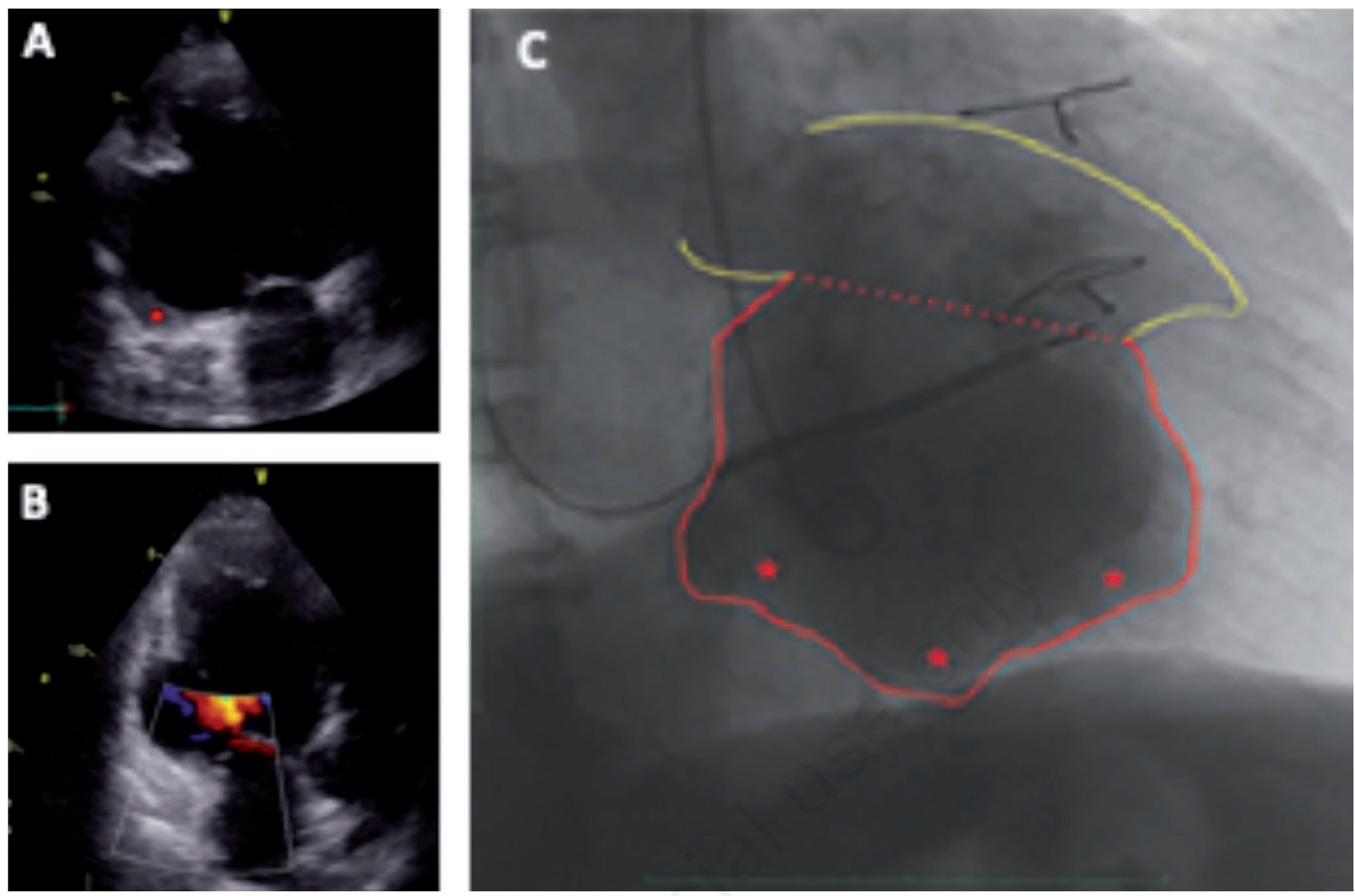

Figure 1. Multimodal imaging of left ventricular pseudoaneurysm (LVP). A) Apical 3-chamber view on transthoracic echocardiography demonstrated a large inferolateral LVPA containing thrombus (asterisk). B) Color-flow Doppler echocardiography and (C) left ventriculography showed evidence of flow across the LV wall defect.

in different case series), trauma or cardiac surgery [1-3]. Other less common causes include infective endocarditis and congenital submitral aneurysm. In contrast to true aneurysms in which myocardial wall integrity is preserved, pseudoaneurysms are contained by pericardium and adherent fibrous tissue, tending to expand and rupture over the time. As described in this case, inferolateral walls are much more affected than anterior walls [3]. This seems to be related to the fact that anterior rupture leads more likely to cardiac tamponade, with subsequent cardiogenic shock and sudden death than posterior rupture (more frequently contained by pericardium). With recent improvement in coronary revascularization, the incidence of this condition is dramatically decreased. However, due to high mortality risk, it is essential an early diagnosis at emergency department in order to plan surgical treatment and improve clinical outcomes. Indeed, a conservative management of this condition carry a mortality rate of nearly $50 \%$ at 2 years [4], which is reduced to $<10 \%$ by surgical correction [5].

Clinical diagnosis may be challenging, since clinical signs, symptoms and first-line assessments are frequently non-specific. At emergency department, during patient's hemodynamic stabilization, point of care trans-thoracic echocardiography is crucial, guiding early diagnosis of LVP and cardiac tamponade [6]. Then, cardiac CT and MRI represents the preferred imaging techniques to distinguish pseudoaneurysm from true aneurysm, which have a distinct physiopathology, clinical features and surgical implications.
Even if medical treatment has been promoted in the past for patients at high surgical risk with incidental finding of LVP, surgical management represents the first-line treatment in symptomatic patients with recently diagnosed LVP or with large $(>3 \mathrm{~cm})$ and expanding LVP [7]. For smaller pseudoaneurysms in high-risk patients requiring re-cardiovascular surgery, percutaneous approach may be preferable [8]. In our case, the patient presented with recurrent giant LVP (maximum diameters $12 \times 5.5 \times 9.5 \mathrm{~cm}$ ) in absence of a narrow neck; therefore, we decide to perform surgical ventricular restoration.

Finally, recurrent LVP after previous surgical restoration are particularly rare and literature data are limited to case-reports and small case-series [9-11]. The most common causes of LVP recurrence are infection, myocardial infarction in adjacent breakable areas and patch or suture dehiscence, as shown in our case.

\section{Conclusions}

Left ventricular pseudoaneurysm is a rare but life-threatening clinical condition. At emergency department, ventricular tachycardia may be the first and unique clinical presentation of LVP late recurrence, whose management requires a multimodality imaging approach to guide surgical correction. 

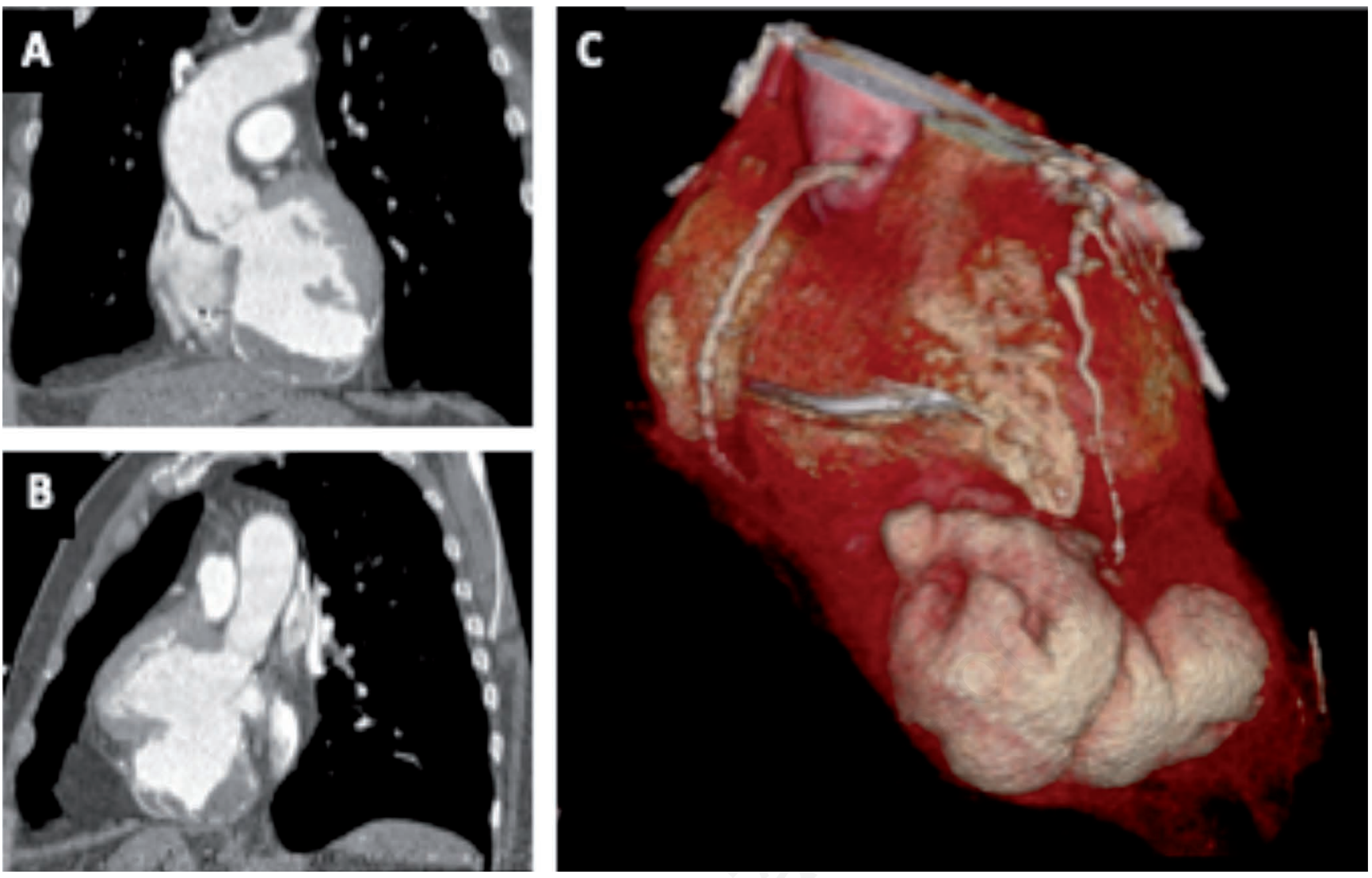

Figure 2. A,B) Volume-rendered cardiac computed tomography (CT) revealed a giant pseudoaneurysmatic lesion close to the mitral valve annulus with a thrombotic layer (asterisk). C) 3D CT reconstruction added information on the size and spatial orientation of the pseudoaneurysm.

\section{References}

1. Frances C, Romero A, Grady D. Left ventricular pseudoaneurysm. J Am Coll Cardiol 1998;32:557-61.

2. Atik FA, Navia JL, Vega PR, et al. Surgical Treatment of postinfarction left ventricular pseudoaneurysm. Ann Thorac Surg 2007; 83:526-31.

3. Yeo TC, Malouf JF, Oh JK, Seward JB. Clinical Profile and outcome in 52 patients with cardiac pseudoaneurysm. Ann Intern Med 1998;128:299-305.

4. Csapo K, Voith L, Szuk T, Edes I, Kereiakes DJ. Postinfarction left ventricular pseudoaneurysm. Clin Cardiol 1997;20:898903.

5. Komeda M, David TE. Surgical treatment of postinfarction false aneurysm of the left ventricle. J Thorac Cardiovasc Surg 1993;106:1189-91.
6. Faustino M, Ranchordás S, Abecasis J, et al. Left ventricular pseudoaneurysm - a challenging diagnosis. Rev Port Cardiol 2016;35:373.e1-6.

7. Prêtre R, Linka A, Jenni R, Turina MI. Surgical treatment of acquired left ventricular pseudoaneurysms. Ann Thorac Surg 2000;70:553-7.

8. Dudiy Y, Jelnin V, Einhorn BN et al. Percutaneous closure of left ventricular pseudoaneurysm. Circ Cardiovasc Interv 2011; 4:322-6.

9. Perrotta S, Lepore V, Flinck A, et al. Left thoracotomy for recurrent left ventricular pseudoaneurysm. J Cardiovasc Med 2013;14:474-6.

10. Marla R, Nicolosi AC. Necessitating, recurrent pseudoaneurysm of the left ventricle. Ann Thorac Surg 2010;89:642.

11. Arnáiz-García ME, González-Santos JM, Iscar-Galán A, et al. Postoperative recurrence of postinfarction true and false ventricular aneurysms. Rev Port Cardiol 2016;35:311.e1-e3. 